๑ Entomologica Fennica. 28 December 2001

\title{
Agrotis iremeli sp. n. from the southern Ural Mountains, with description of the larval stage (Lepidoptera: Noctuidae)
}

\author{
Kari Nupponen, Matti Ahola \& Jaakko Kullberg
}

\begin{abstract}
Nupponen, K., Ahola, M. \& Kullberg, J. 2001: Agrotis iremeli sp. n. from the southern Ural Mountains, with description of the larval stage (Lepidoptera: Noctuidae). — Entomol. Fennica 12: 217-226.
\end{abstract}

Agrotis iremeli sp. n. is described from the mountains Iremel and Nurgush in the southern Ural Mountains. Altogether 64 specimens were reared from larva and pupa in two localities during three different years. Both habitats were highly isolated mountain tundra regions at an elevation of 1300-1400 m. Also larval and pupal stages of the species are described. The moth belongs to the fatidica-group being a close relative to A. ruta (Eversmann, 1851). The new taxon differs from the latter by basally narrower, more unicolorous and dark reddish brown forewings with indistinct pattern, but also by the details in the structure of male and female genitalia. The larval stage indicates a relationship to A. clavis (Hufnagel, 1766). The adult, male and female genitalia, larval chaetotaxy, pupa and habitat are illustrated.

Kari Nupponen, Miniatontie 1 B 9, FIN-02360 Espoo, Finland; E-mail: Kari.Nupponen@kolumbus.fi

Matti Ahola, Metsänreunantie 27 G, FIN-85900 Reisjärvi, Finland

Jaakko Kullberg, Finnish Museum of Natural History, Division of Entomology, P.O. Box 17, FIN-00014 University of Helsinki, Finland

Received 18 June 2000, accepted 12 September 2001

\section{Introduction}

The genus Agrotis Ochsenheimer, 1816 is a large genus in the subfamily Noctuinae. In the Palaearctic region, 80 species are recorded, of which 32 have been found in Europe (Fibiger 1990). Most species occur in open habitats and the larvae feed on the roots of grasses and other herbaceous plants, or hide below the surface of the soil by day and come up to feed on the foliage after dark. The large genus is divided into species-groups, but the genitalia structure is very constant in the genus, providing no reliable characters for describing the species-groups as new genera or subgenera (Fibiger 1997).
A new taxon of this genus was found from the mountain Iremel in the southern Ural Mountains. A small series was reared from pupa in 1997 and further specimens from larva in 1999 and 2001 in the same locality. In 2001 a new population of the same species was found in the mountain Nurgush, about $40 \mathrm{~km}$ NNE from Iremel. On the basis of the genitalia and the shape of wings the taxon belongs to the fatidica species-group, being a close relative to A. ruta (Eversmann, 1851). However, the larval stage indicates also a relationship to the segetum-group being close to $A$. clavis (Hufnagel, 1766). The new taxon, its larval and pupal stages are described. 


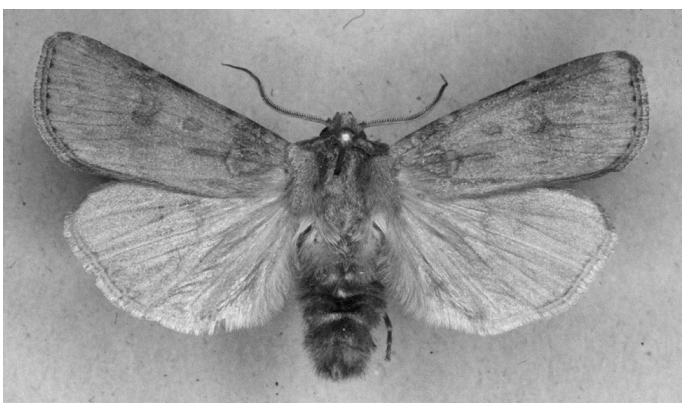

Fig. 1. Male of Agrotis iremelisp. n. (holotype).

\section{Description}

\section{Agrotis iremeli sp. n.}

Type material. Holotype $0^{7}$ (Fig. 1): Russia, southern Urals, $54^{\circ} 32^{\prime} \mathrm{N} 58^{\circ} 51^{\prime} \mathrm{E}$, Cheliabinsk oblast, Iremel Mountain $1300 \mathrm{~m}$, dry mountain tundra, larva 26.-27.VI.1999, emerged 06.-12.VII.1999, T. \& K. Nupponen leg. In coll. T. \& K. Nupponen.

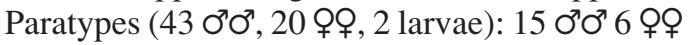
same data as holotype. Same locality as holotype: 4 O’ర $^{7} 2$ 우 pupa 14.VII.1997, emerged 16.-20.VII.1997, K. Nupponen \& J.-P. Kaitila leg.; 2 O $^{7} \sigma^{7} 1$ 오 same data as previous paratypes (see Remarks); 7 'ౌ 3 우 larva 17.VI.2001, emerged 04.-14.VII.2001, K. Nupponen leg. Same locality: 2 larvae preserved in ethanol: 1 larva 27.VI.1999, T. \& K. Nupponen leg.; 1 larva

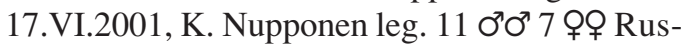

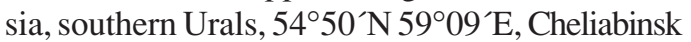
oblast, Nurgush Mountain 1300-1400 m, dry mountain tundra, larva 23.VI.2001, emerged 08.15.VII.2001, K. Nupponen \& V. Olschwang leg. Same data as previous paratypes except collectors: $20^{7} 0^{7} 1$ \& G. Stangelmaier leg., $20^{7} \sigma^{7} \mathrm{C}$. Wieser leg. Genitalia preparations: J. Kullberg prep. no. 1/01.VI.2000 (Q), 2/01.VI.2000 (Q), 3/

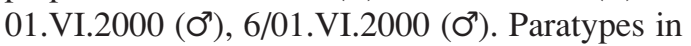
the collections of T. \& K. Nupponen, J.-P. Kaitila, M. Ahola (incl. larvae), J. Junnilainen, G. Stangelmaier, C. Wieser and M. Fibiger.

\subsection{Description of imago}

Diagnosis. Imago. The taxon is rather easy to separate from other known Agrotis species by the ex-

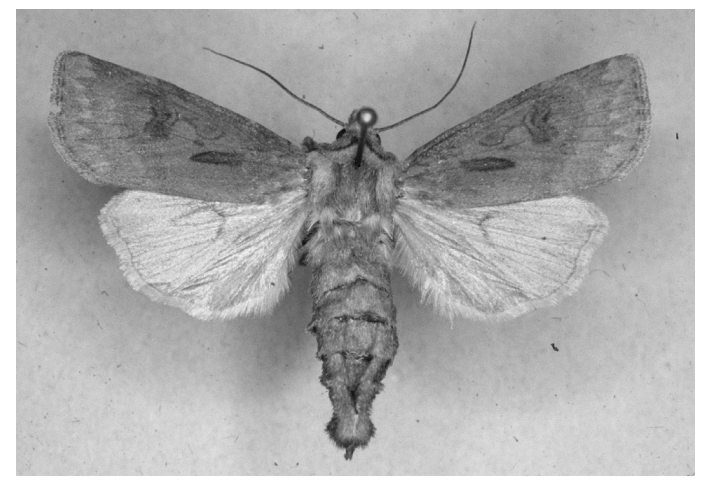

Fig. 2. Female of Agrotis iremeli sp. n. (paratype).

ternal appearance. Agrotis iremeli sp. n. is habitually a stable species showing only minor variation in coloration and wing pattern. The ground colour of the forewing is dark reddish brown, seldom a little bit paler, and sharpness of stigmata varying from rather distinct to more or less invisible. Both sexes have wings of normal length (Figs. 1-2). Large size and forewings with more or less unicolorous ground colour and indistinct pattern are characteristic for the species. In the other species of the fatidica-group, forewings are basally broader, more greyish with distinct pattern and pale colour around veins. Agrotis characteristica Alphéraky, 1892 sometimes has a similar shape of forewing, but its hindwings are much paler. Some forms of $A$. ruta and A. chretieni (Dumont, 1903) are also rather similar to iremeli, but they are more mottled, stigmata usually darker and forewings always greyish. A variable A. cinerea (Denis \& Schiffermüller, 1775) can have similarly coloured forewings, but hindwings of male are paler and the moth is much smaller in size. The species in the segetum-group are also smaller and less robust in appearance, having narrower, apically sharper forewings, paler hindwings and longer pectination in the antenna.

Male genitalia (Fig. 3). Valvae similar to that of A. ruta (Fig. 4), but because of great variation and wide geographical distribution it is difficult to find good diagnostic characters. However, the valva appears to be somewhat shorter and the cucullus less rounded than in A. ruta. The clasper is situated more in the middle part of valva than in A. ruta. Probably the form of the clasper is not a good diagnostic character, as it seems to vary also among a single population of $A$. ruta. The 

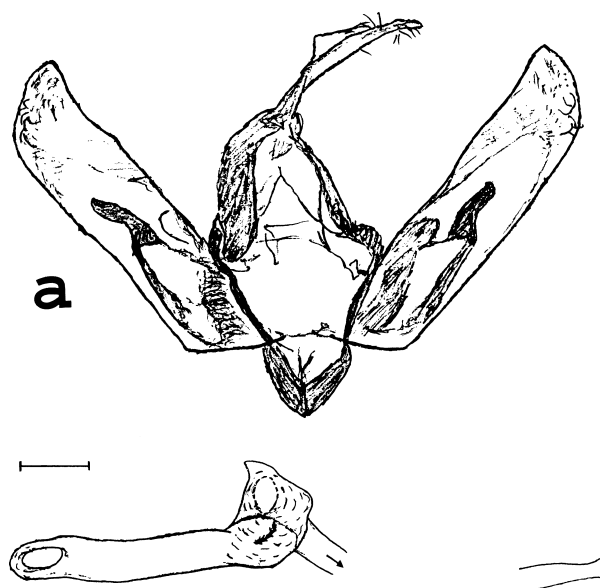

b

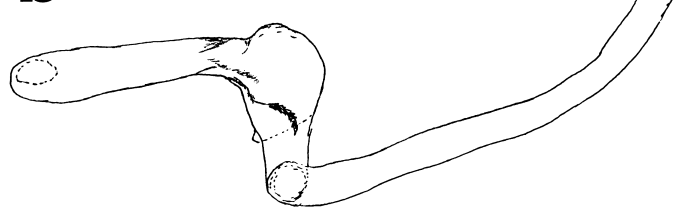

Fig. 3. Male genitalia of $A$. iremeli sp. n. - a. Valvae (paratype; prep. no. 6/01.VI.2000 JK). - b. Aedeagus with everted vesica (paratype; prep. no. 3/01.VI.2000 JK). Scale $1 \mathrm{~mm}$.

best diagnostic characters exist in the vesica. Both A. iremeli and A. ruta share common characters, but there are good differences especially in the angles of the vesica. Dorsally the forms of the basal swelling and subbasal diverticulum are wider in $A$. iremeli with a stouter lateral tip. From the dorsal view it is also possible to see that the opening of the vesica tube in the subbasal diverticulum is vertically oval in A. iremeli and horizontally oval in A. ruta. Also the angle of the vesica is clearly different, which is easier to see from the ventral side. In $A$. iremeli the angle goes almost $90^{\circ}$ upwards and bends another $90^{\circ}$, which makes that part of the vesica tube almost parallel to the anticlockwise aedeagus and forming a curve backwards. In A. ruta the angle is clearly more than $90^{\circ}$, causing the vesica tube to curve ventrally over the basal diverticulum and itself forming a clockwise curve backwards. Note: in different $A$. ruta populations the length of the vesica tube can vary remarkably, but the angles remain the same.

Female genitalia (Fig. 5). The genitalia are similar to those of A. ruta (see Fibiger 1997), ex-
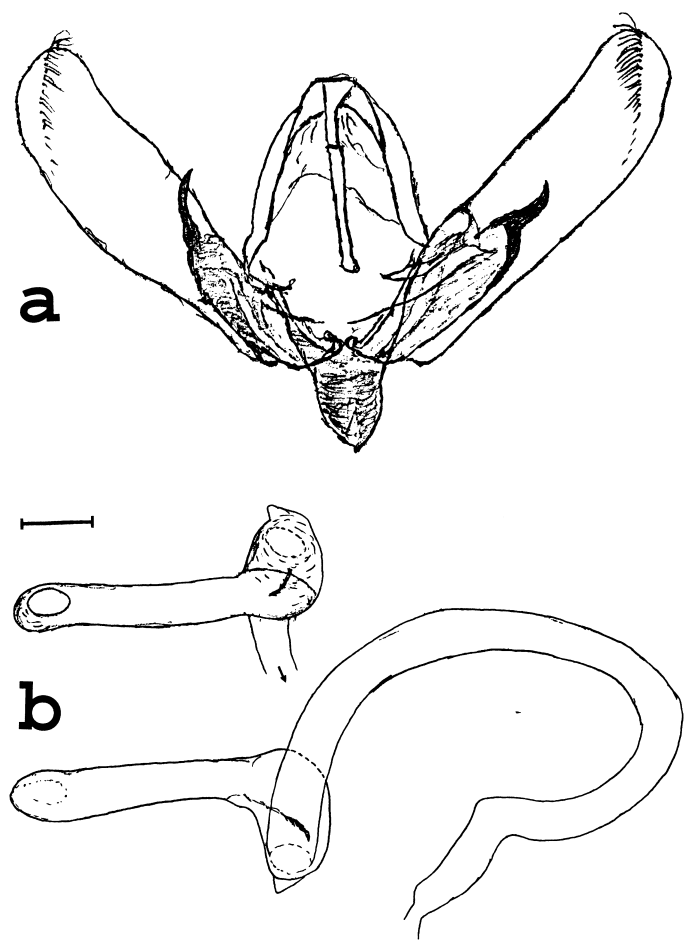

Fig. 4. Male genitalia of $A$. ruta (Ev.) (Russia, Buryatia; prep. no. 4/01.VI.2000 JK). - a. Valvae. - b. Aedeagus with everted vesica. Scale $1 \mathrm{~mm}$.

cept ductus bursae is somewhat wider in the middle part. Vice versa, A. ruta has a narrow ductus bursae with a hump near the opening to the sack of bursa, which makes the opening as wide as in A. iremeli. The sack of bursa is shorter and the first $1 / 5$ of the appendix bursae connected to the sack of bursa is clearly wider in A. iremeli, and the spiral form of appendix bursae is more rounded.

Description of imago. Wingspan: male 38.5-43 mm; female 40-44 mm. Antenna in male bipectinate, anterior pectination $0.6 \times$ length of posterior one; in female filiform. Head dark reddish brown. Labial palpi coloured same as head, segment I and II of equal length, ventrally with long, hair-like scales; segment III $0.7 \times$ length of segment II. Basal half of collar dark reddish brown; at middle narrow blackish brown band; terminal part pale fuscous, distally darker. Legs dark brown, tibia and tarsus darker than femur, with following pale beige ring-shaped markings: end of tibia; basal and apical 1/4 of spurs in hindlegs and midlegs; 5 narrow, indistinct rings 


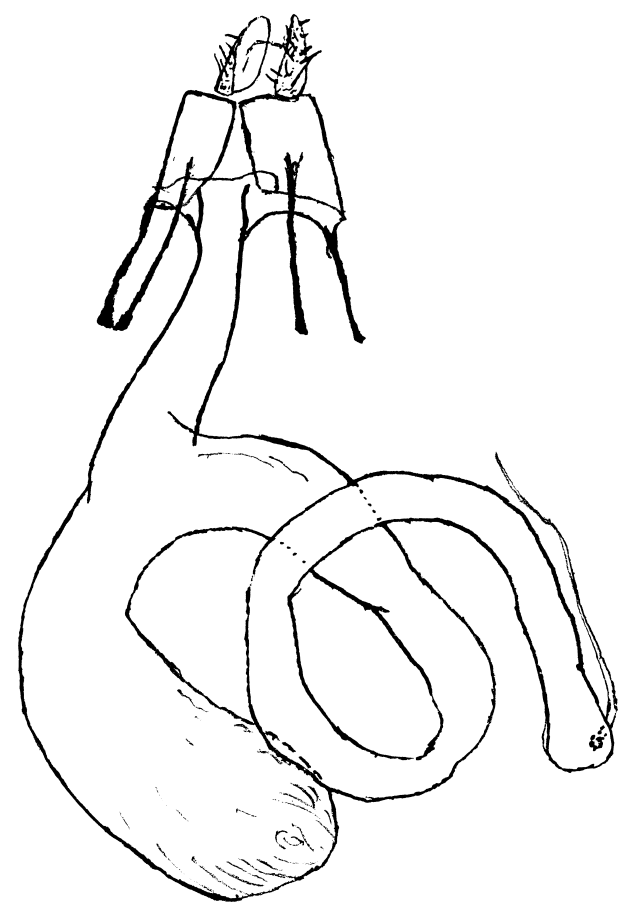

Fig. 5. Female genitalia of $A$. iremeli (paratype; prep. no. 1/01.VI.2000 JK).

in tarsus. Thorax and abdomen reddish brown mixed with grey, slightly paler than forewing. Forewing ground colour dark reddish brown. Veins black, indistinct, more visible in marginal field. Antemedian line double, only visible near claviform. Postmedian line very indistinct, weakly jagged. Subterminal line indistinct and jagged, often with more or less indistinct wedge-shaped marks. Terminal line expressed as dark dots between veins, in some specimens absent. Fringe light brown, paler than forewing, with darker medial fascia. Stigmata more or less indistinct with blackish outline, coloured same as forewing, reniform with darker brown median suffusion; orbicular annular or slightly flattened, reniform with normal shape, claviform elongate and narrow. In outer part of median field broad, moderately indistinct fascia over wing through reniform stigma. Hindwing with discal spot, fuscous, basally more or less pale; underside pale fuscous, terminally darker, with discal spot and rather indistinct medial fascia.

Description of male genitalia (Fig. 3). Uncus strong, longer than tegumen. Saccus wide, sub- triangular. Sacculus well sclerotized, ending to more strongly sclerotized clasper. Clasper thumblike, 0.2 length of sacculus, situated in middle part of valva; basally wide, tapering upwards before changing its direction more downwards in middle part; tip stout. Costal margin of valva more strongly sclerotized than weak and irregular ventral margin. Cucullus weakly rounded and in tip of valva pointed. Corona irregular with small and short setae. Aedeagus with more sclerotized tip on ventral side; vesica extremely long, three-dimensional, $5 \times$ length of aedeagus. Vesica (on ventral side): Basal swelling rounded forming small hump laterally at left, opening to vesica tube through subbasal diverticulum at right; subbasal diverticulum as wide as basal swelling, pointing to right, distally tapered and hidden behind vesica; on dorsal side subbasal diverticulum more visible, pointing to left forming wide sack with opening of vesica tube at bottom. Near tip of aedeagus strongly sclerotized band of small spines bent to same direction as vesica. Ventrally tube of vesica first pointing to right, then forming strong $90^{\circ}$ angle upward and then bends forward to same parallel direction as aedeagus, making wide curve pointing back against aedeagus and widening to apical swelling before ending vesica ejaculatorius.

Description of female genitalia (ventral side) (Fig. 5). Papillae anales triangular and hairy with strong subbasal setae. Apophyses strong, posterior $1.5 \times$ length of anterior. Ductus bursae long, widening strongly when opening to bursa. Bursa divided into two parts: sack of bursa (on left) and appendix bursa (on right). Sack of bursa massive, more than $2 \times$ wider and $1.3 \times$ longer than ductus bursae. Appendix bursae making full $360^{\circ}$ spiral ventrally clockwise; $2.5 \times$ longer, but clearly narrower than sack of bursa. Opening and basal 1/5 of corpus bursae widened clearly, second $1 / 5$ only little. Ductus seminalis opening dorsally near tip of appendix bursae.

Bionomy. Both known habitats are grassy, dry mountain tundra with sparse rocks and stones at an elevation of 1300-1400 m. The locality in Iremel was a low ridge $(100 \mathrm{~m} \times 300 \mathrm{~m})$ between higher peaks, surrounded by taiga forest (Fig. 6). In Nurgush the species occurred on the top of the mountain. All specimens were reared from pupa or larva, which were found under rather small stones (diameter $10-50 \mathrm{~cm}$ ) that were surrounded 
Fig. 6. The habitat of $A$. iremeli in S Ural.

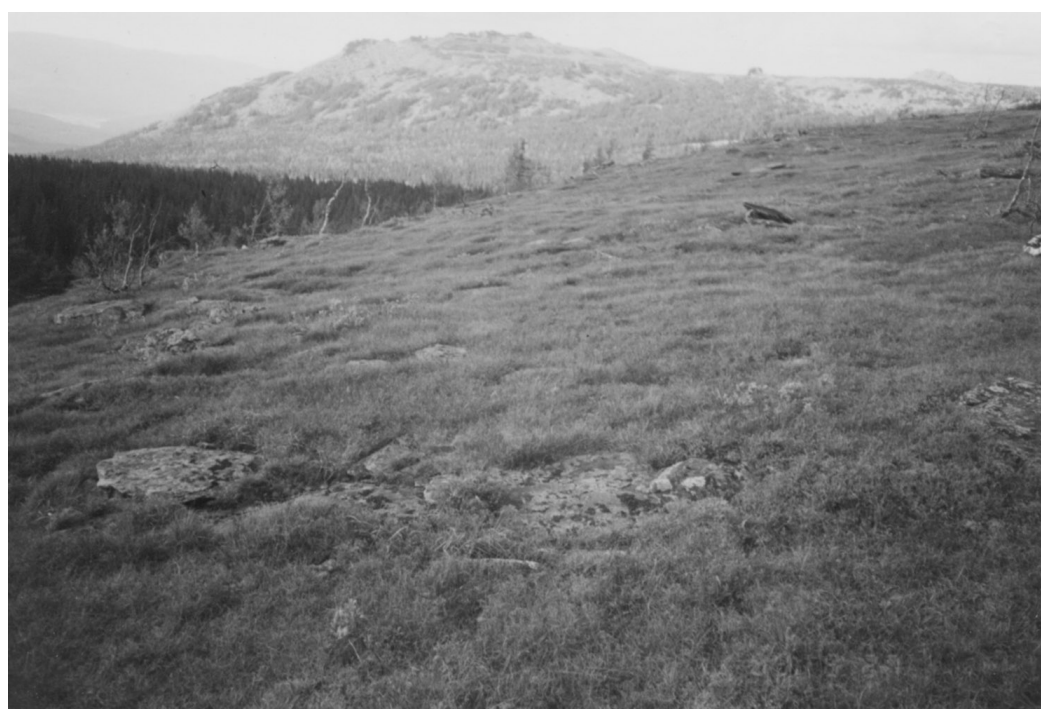

by grasses. In addition, 2 larvae were found running on the stone. The specimens typically preferred flat stones that were lying perpendicularly to the afternoon sunshine in such a position that the area underneath the stone is well aerated. The microclimate around and below such stones tends to be much warmer than the surrounding area in sunny weather, which is probably important for the development of larva in mountain habitats. 14 pupae were found on 14.VII.1997 and the specimens emerged during 16.-20.VII.1997. The second portion of specimens, 1 pupa and about 25 larvae which were just pupating, were collected in the same locality during 26.-27.VI.1999 and the moths emerged during 06.-12.VII.1999. In the early year 2001, pupae and pupating larvae were recorded already at 17.VI. in Iremel and at 23.VI. in Nurgush, and the moths emerged during 04.15.VII. The duration of the pupal stage on the last rearing was long probably because the pupae were kept at high altitude $(2300 \mathrm{~m}$ a.s.l. in the Altai Mountains) and moderately cold weather. Our rearings indicate that the flight period in nature is from the middle of July to the first third of $\mathrm{Au}$ gust. The host plant is unknown, but most probably the larva feeds on low grasses (see Remarks). The larvae of $A$. iremeli seem to be seldomly attacked by parasitoids. We recorded only two specimens of parasitoids in our rearings. Both of them are males of Coelichneumon sp. (Ichneumonidae: Ichneumoninae, Heresiachini) (V. Vikberg pers. comm.). Many species of the genus Coelichneumon Thomson have previously been recorded as parasitoids of Noctuidae. The species of that genus are difficult to determine and include many rarities. The parasites emerged a few days later than the moths (1 $0^{7} 15$. VII., $10^{\prime \prime} 16$. VII.).

Distribution. Russia (S Ural). The taxon is known from two different localities in the mountain range of the southern Urals: Iremel and Nurgush.

Etymology. The species name refers to the type locality, the mountain Iremel, where the taxon was found in 1997.

Remarks. A remarkable portion of the emerged moths was deformed, which might be a sign of a highly isolated population or a relict. The deformation was not connected to rearing conditions, because the pupal abnormalities were visible already in nature.

The flora is rather poor but very characteristic in both known localities of $A$. iremeli sp. n. In the Mountain of Iremel, the plants occurring in the habitat were investigated in June 2001. The following shrubs and herbs were recorded: Salix glauca L., Juniperus sibirica Burgsd., Betula tortuosa Ledeb., Carex rupestris All., Festuca igoschiniae Tzvel. (*), Carex ensifolia Turcz. \& V. Krecz., Vaccinium uliginosum L., Vaccinium vitis-idaea L., Polygonum viviparum L., Anemone biarmiensis Juz. (*), Lagotis uralensis Schischk. (*), Pedicularis oederi Vahl, Pachypleurum 
alpinum Ledeb., Gypsophila uralensis Less. (*), Patrinia sibirica (L.) Juss., Juncus trifidus L., Lloydia serotina (L.) Reichenb., Saussurea controversa DC. The taxa that are endemic to the southern Urals are marked with an asterisk $(*)$. The most common plants in the locality were Carex rupestris, Vaccinium uliginosum and Juncus trifidus. Extremely interesting is the occurrence of Festuca igoschiniae in the southern Urals. The taxon is known only from seven isolated localities in the dry mountain tundra habitats, including both known localities of A. iremeli. The occurrence of that plant might indicate a suitable habitat for the moth, and possibly it is a host plant or one of the host plants of A. iremeli. There exist only a few suitable habitats for $A$. iremeli in the southern Ural region, and the spots are often located far from each other. The nearest corresponding tundra habitats are found in the northern Urals, over $600 \mathrm{~km}$ north from Iremel.

We tried to get females to lay eggs in the first rearing by putting several deformed specimens in a jar, but without success. Later these specimens were partly destroyed in the mail, but the abdomens were still in good enough condition for making the genitalia preparations. These preparations are included in the type material.

\subsection{Description of larval stage}

Hinton's (1946) nomenclature of the larval chaetotaxy was used in the description of larvae. Names of ornaments of larvae follow Beck (1960, 1974).

Diagnosis. The larva of A. iremeli habitually resembles most those of A. clavis and A. ruta. They have strong frontal and coronal stripes and weak reticulation on the head, the black spot on frons and ventrad from ocelli and the dark first segment of antenna. The body on all three species is dark grey with a large pinacula. They also have a yellowish-brown anal shield. Habitual differences between these larvae are listed in Table 1.

\subsubsection{Larva}

Description. Ornaments: Head yellowish-brown with broad black coronal and frontal stripes joined together (Fig. 7). Other stripes weak, pale brown. Reticulation weak with pale yellowish-brown fields and greyish bands, all groups nearly plain coloured. Black spot ventrad from ocellar area. Frons and adfrons yellowish, black spot on posterior part of frons. First antennal segment blackish, second brown.

Cervical shield with yellow transverse zone between setae XD1 and D1 including setae D2 and reaching laterally to brown spot of tonofibrillary platelets. Anterior part black, including XD1, and XD2 setae. Dark brown spot around D1 setae. Middorsal line narrow, pale grey, subdorsal line absent. Setal points black. Anal shield yellowish-brown with irregular brown colour and black setal points.

Body dark grey with large blackish pinacula. Pinacula L1s larger than spiracles of abdomen, pinacula $\mathrm{D} 2 \mathrm{~s}$ larger than $\mathrm{D} 1 \mathrm{~s}$ on dorsal region. All pinacula separated except those of L1-L2 and SV1-SV2 on prothorax. Setae L2 on prothorax and SD1 in thorax and in 9th abdominal segments weak, hairlike. Lines poorly visible in our material preserved in alcohol. Crochets of prolegs low in number, vary from 10 of $3 \mathrm{rd}$ abdominal segment to 14 of 6th and to 21 of 10th abdominal segments.

Table 1. Habitual differences between the larvae of $A$. iremeli, A. ruta and A. clavis.

\begin{tabular}{|c|c|c|c|}
\hline Character & iremeli & ruta & clavis \\
\hline $\begin{array}{l}\text { Head: } \\
\text { Supraocellar stripe } \\
\text { Ocellar stripe }\end{array}$ & $\begin{array}{l}\text { absent } \\
\text { absent }\end{array}$ & $\begin{array}{l}\text { black, narrow } \\
\text { black, narrow }\end{array}$ & $\begin{array}{l}\text { black, caudally enlarged to neck } \\
\text { black, caudally enlarged to neck }\end{array}$ \\
\hline $\begin{array}{l}\text { Cervical shield: } \\
\text { Yellow transverse zone } \\
\text { on cervical shield }\end{array}$ & $\begin{array}{l}\text { broad, including } \\
\text { D1 and D2 but } \\
\text { not XD1 and XD2 }\end{array}$ & $\begin{array}{l}\text { very narrow on caudal } \\
\text { margin of shield, setae } \\
\text { not included }\end{array}$ & $\begin{array}{l}\text { broad, including also XD1 and } \\
\text { XD2 setae }\end{array}$ \\
\hline
\end{tabular}




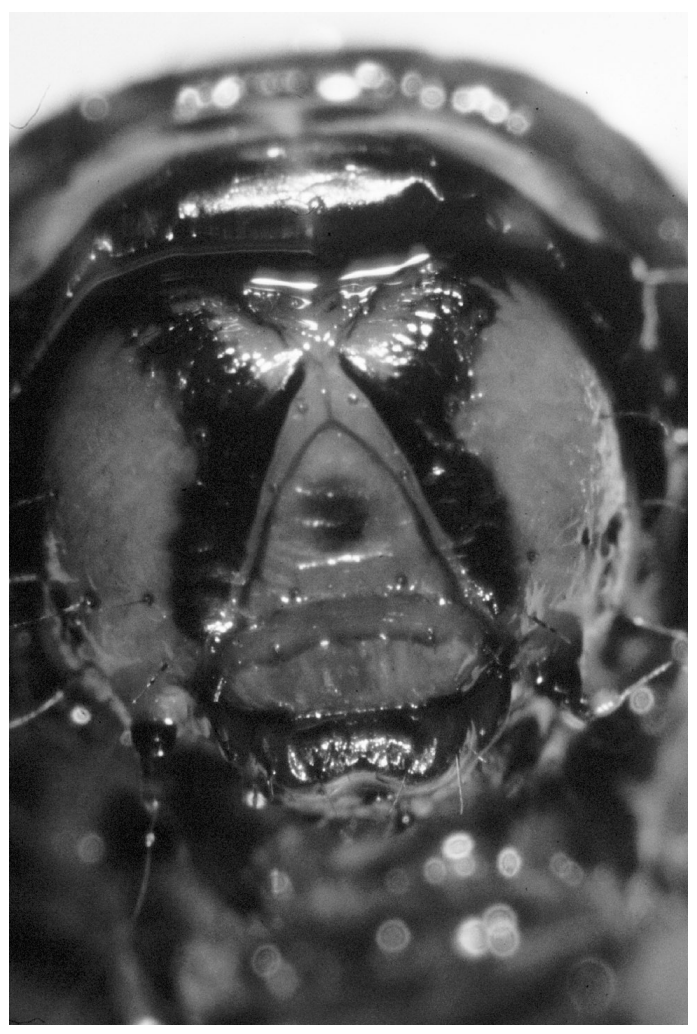

Fig. 7. A. iremeli: head of larva.

Mouthparts (Figs. 8a, 10a): Spinneret shorter than broad, dorsoventrally flattened with bilobed lower lip and with fringed dorsal lip, fringes in two separated groups (Figs. 8-9). Labial palpi rather long, length of Lps 1 about $1.8 \times$ its width and $3 \times$ length of Lp2. Lps 2 short about $1 / 2$ Lp1. Setae Lp1 and Lp2 rather slender, Lp2 about 2.5 Lp1. Stipular setae arising from stipular area in prementum, stout, longer than Lp2 of labial palpus. Hypopharynx covered with stout pluntpointed spines from base of labial palpi to posterior end of premental arms (Fig. 10). Distal region of hypopharynx with stout and long (about $2 \times$ Lp2) spines on lateral group and stout but short (shorter than Lp2) spines in middle of region. Lateral teeth of posterior region in one row with ca. 30 stout, broad, nearly parallel-sided spines, dorsolateral area covered with short (shorter than Lp2) stout, plunt-pointed spines. Medial part of region spinulate only anteriorly. Galeal lobe of maxilla shorter than second segment of maxillary palpus, three sensilla trichodea of galeolacinial

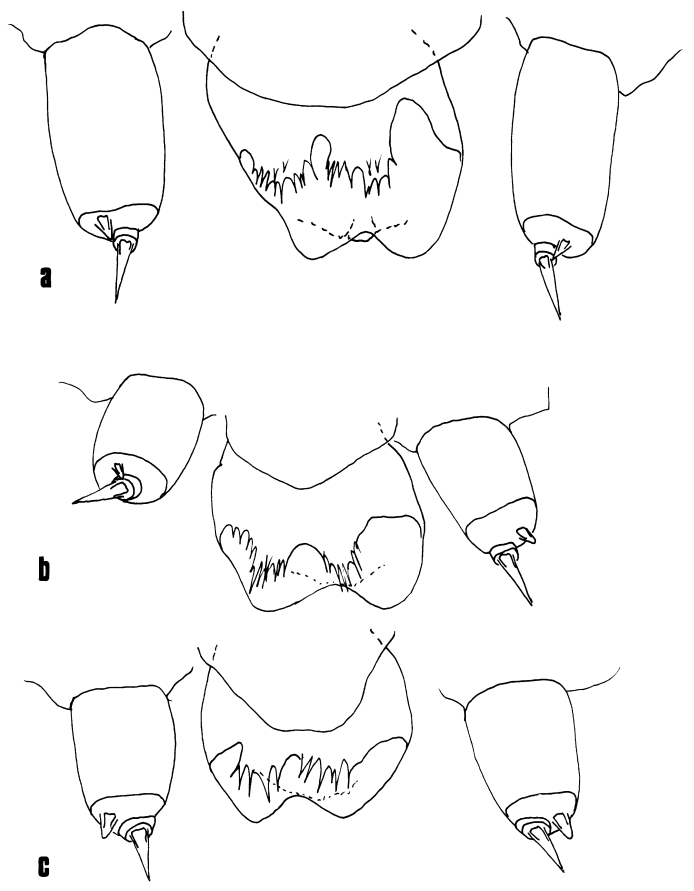

Fig. 8. Spinneret and labial palpi of $A$. iremeli and segetum-group in the dorsal view. - a. A. iremeli. b. A. segetum. - c. A. clavis. Scale $0.1 \mathrm{~mm}$.

lobe equal in length, weak stipital sack present on dorsal part of stipes. Labrum with shallow notch (Fig. 11). Mandible without inner tooth, six teeth of cutting margin present (Fig. 12).

\subsection{Description of pupa}

Pupa dark brown or blackish brown (Fig. 13). Labial palpi with rounded sides present on labium. Proboscis exceeding caudal margin of abdominal segment IV. Postclypeus differentiated, transverse furrow present between it and labrum, frons without protuberances. Sutures strongly developed, blackish. Limit between oculus and proboscis very short, suture between oculus and foreleg dorsally shortly forked, limit between forelegs and antennae rather short, shorter than that between proboscis and dorsal part of foreleg. Metanotum dorsally smooth, laterally rather rounded. Veins of forewings weak or absent, hindwings reaching caudal margin of abdominal segment III. Spiracles of abdomen broad, prominent. Structure of cre- 


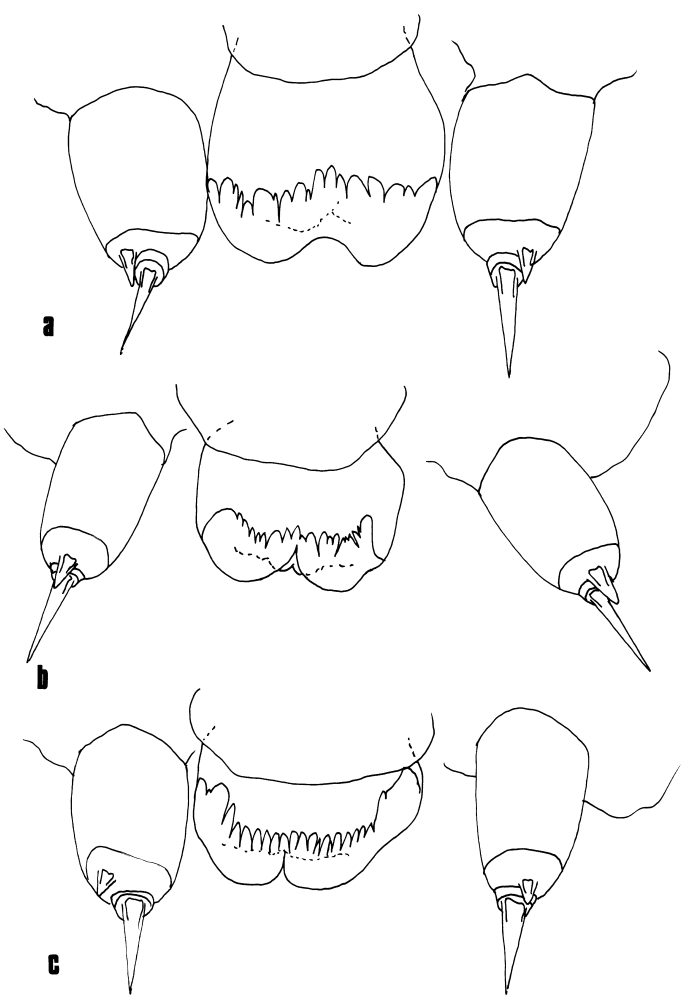

Fig. 9. Spinneret and labial palpi of fatidica-group in the dorsal view. - a. A. fatidica. - b. A. ruta. - c. A. chretieni. Scale $0.1 \mathrm{~mm}$.

master weak on dorsal side, ventrally with rounded depression. Setae D2 rather close together, always present, stout, more or less bifurcate on top; other setae (D1, L1, SD1) weak, setose, arising from rough pinacula, seldom present, mostly absent and only pinacula visible (Fig. 14).

\section{Discussion}

The taxa of the fatidica-group are montane, boreoalpine species, most of them occurring in mountainous regions. The segetum-group is not a phylogenetically well-defined group, but includes only superficially similar species. A. iremeli is a close relative of $A$. ruta. Despite more unicolorous habitus they belong to the fatidica-group on the basis of imaginal characters together with $A$. fatidica (Hübner, 1824), A. luehri (Mentzer \& Moberg, 1987), A. chretieni, A. characteristica and A. trifurca Eversmann, 1837 (Fibiger 1990, 1997).

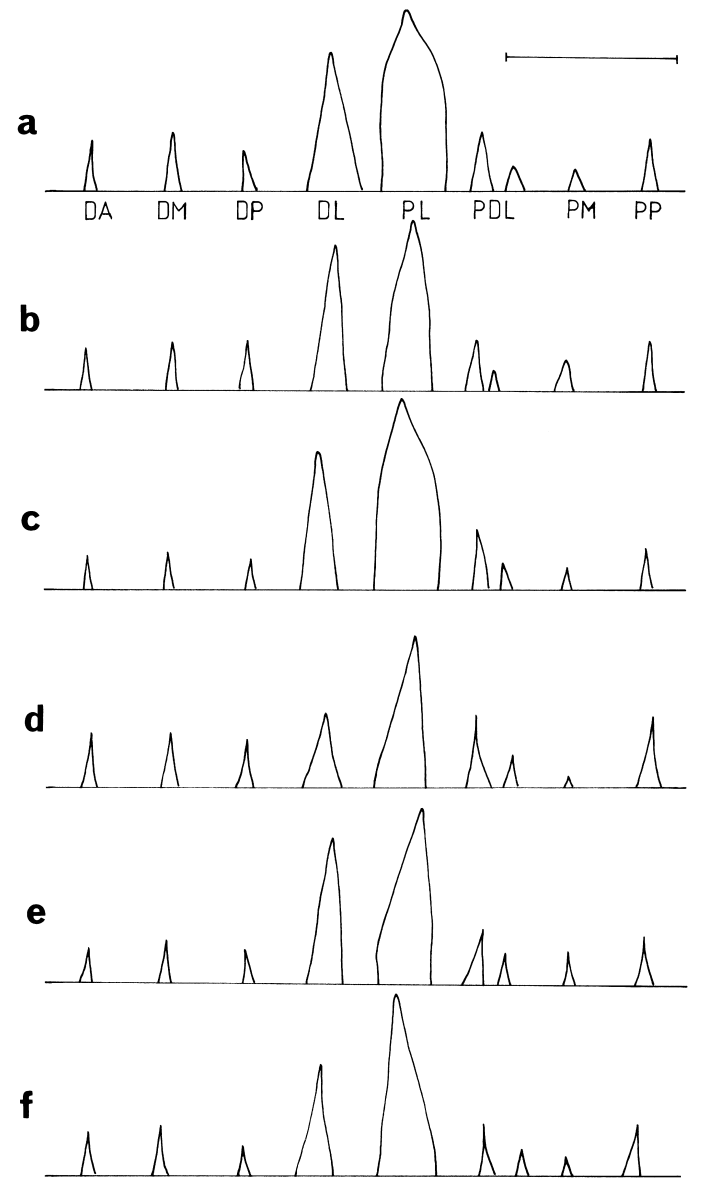

Fig. 10. Schematic drawings of hypopharyngeal spines of $A$. iremeli and compared species. - a. A. iremeli. -b. A. segetum. - c. A. clavis. - d. A. ruta. - e. A. fatidica. - f. A. chretieni. Abbreviations: $\mathrm{DA}=$ anterior spines of distal region, $\mathrm{DM}=$ medial spines of distal region, $\mathrm{DP}=$ posterior spines of distal region, $\mathrm{DL}=$ lateral spines of distal region, $\mathrm{PL}=$ lateral tooth of posterior region, $\mathrm{PDL}=$ dorsolateral spines of posterior region, $\mathrm{PM}=$ medial spines of posterior region, $\mathrm{PP}=$ hindermost lateral spines of posterior region. One of the largest spines of each group is drawn, except two spines (biggest and weakest) of PDL group. Scale $0.1 \mathrm{~mm}$.

Eversmann described Orthosia murina Ev., 1848 from the southern Urals. The taxon is considered as synonymous to Agrotis cinerea (Denis \& Schiffermüller, 1775) (e.g. Kozhanchikov 1937). The first author examined Eversmann's original material of murina preserved in the Zoological Institute, St. Petersburg. There are three specimens of the taxon in Eversmann's 
Fig. 11. A. iremeli: Inner surface of the left mandible. Scale $0.1 \mathrm{~mm}$.

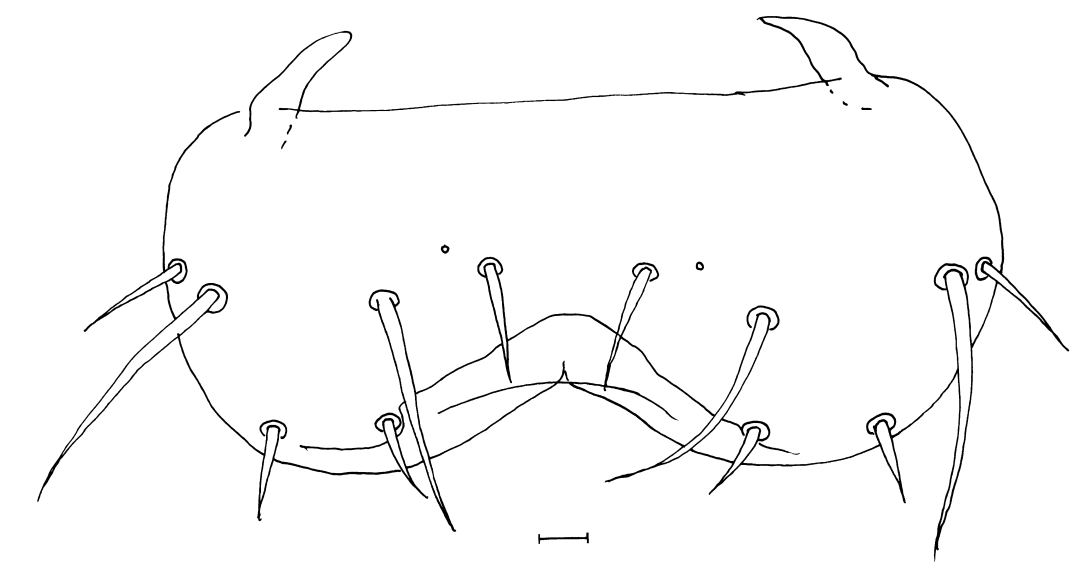

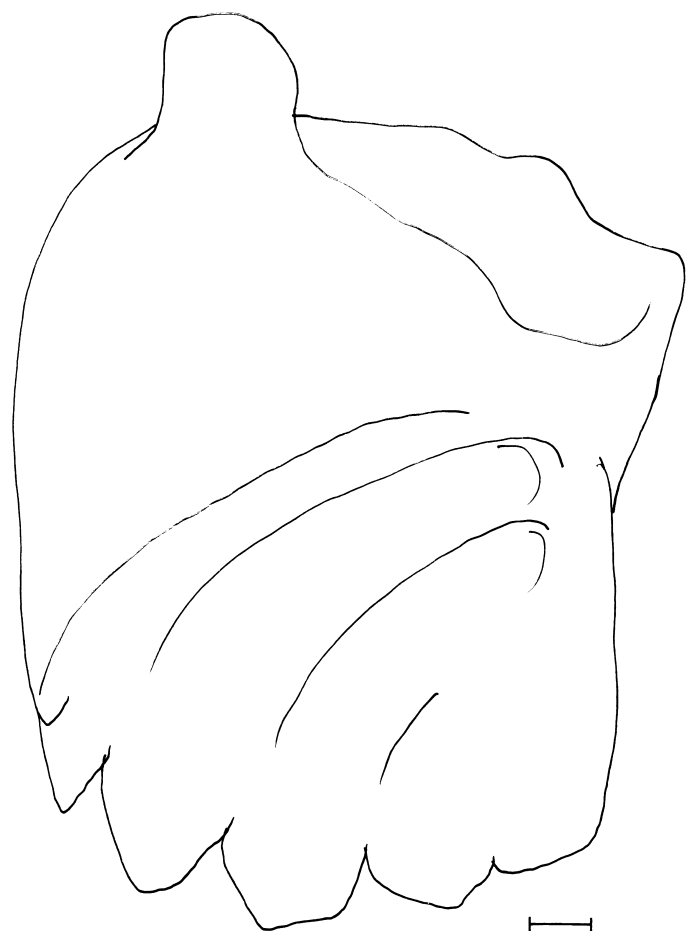

Fig. 12. A. iremeli: Labrum in the frontal view. Scale $0.1 \mathrm{~mm}$.

collection labelled as follows: Male, labelled "Spassk.[oye]; murina Evm.; coll. Eversmann"; Female, labelled "Spassk. [oye]; cinerea; coll. Eversmann"; Female, labelled "Boisd.[uval]; $\mathrm{ci}$ nerea; coll. Eversmann". The male is probably the type of $O$. murina Ev. All three specimens belong to the taxon A. cinerea (D. \& Sch.) without doubt. Two of them have been collected in

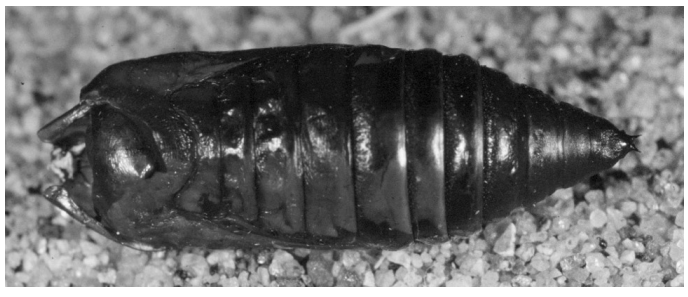

Fig. 13. Pupa of $A$. iremeli, dorsal view.

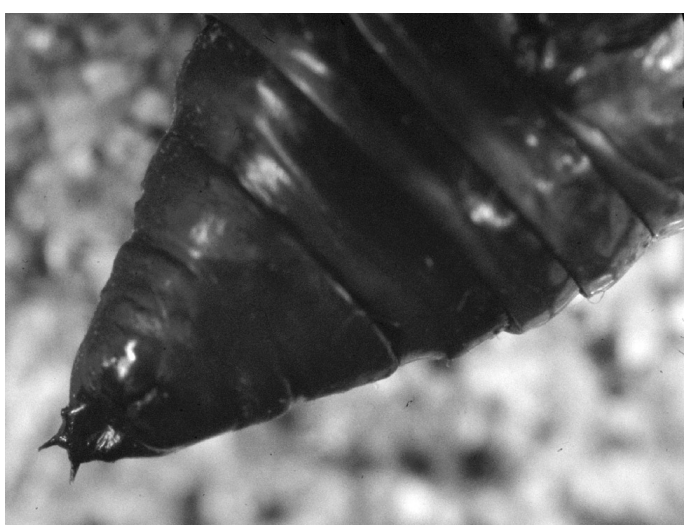

Fig. 14. Pupa of $A$. iremeli, cremaster.

Spasskoye village located at the southern foothill region of the Ural Mountains. However, $A$. cinerea is a rather common species everywhere on the foothill steppes of the southern Urals. It is even possible that Eversmann did not have any material from the highlands of the southern Ural Mountains, because he has not reported any of the characteristic mountain tundra spe- 
cies from there. Thus, the taxon Orthosia murina Ev. does not have anything to do with A. iremeli sp. n.

In comparison with habitus of the available larval material of A. fatidica and A. chretieni, also the larva of A. iremeli seems to be close to A. ruta. The morphology of larval mouthparts of this group showing some characters in common, e.g. dorsal lip of spinneret fringed, fringes arranged in one group, seta Lp2 of labial palpi stout and rather long, spines of hypopharynx sharp-pointed and lateral teeth of posterior region triangular. Based on these characters $A$. iremeli differs from the fatidica-group. Morphologically closest relatives of $A$. iremeli seem to be in the segetum-group (compared with $A$. segetum and A. (lavis). Characters of segetumgroup are as follow: fringes of lower lip of spinneret arranged in two groups; seta Lp2 of labial palpus relatively shorter; spines of hypopharynx broad and blunt-pointed; lateral teeth of posterior region of hypopharynx with parallel sides. Length of segment I of labial palpus of A. iremeli is longer than that in the segetumgroup. Unfortunately the larvae of A. incognita Staudinger, 1888 and some other Asian species are unknown and therefore comparison is impossible. However, mouthparts of A. iremeli most resemble those of $A$. clavis, although the habitus is closer to $A$. ruta.

The pupa of iremeli resembles that of the segetum-group, mostly because of the structure of the cremaster. In this group, D2 setae are stout and located rather close together, other setae being weak or absent. The cremaster of fatidicagroup has both D1 and D2 setae stout and D2 situated more separated (Patocka 1996).
Acknowledgements. We thank Dr. Vladimir Olschwang (Ekaterinburg, Russia) for organizing the southern Ural expeditions and Mr. Pavel Kulikov (Ekaterinburg, Russia) for botanical information on the visited localities, as well as Mr. Jari-Pekka Kaitila (Vantaa, Finland) and Mr. Timo Nupponen (Espoo, Finland) for valuable help in collecting the type material. Our thanks are also due to the following accompanying persons: Mr. Jari Junnilainen (Vantaa, Finland), Dr. Alexander Lagunov (Miass, Russia), Mr. Alexander Malozemov (Ekaterinburg, Russia) and Mrs. Elena Nupponen (Espoo, Finland). Finally, we thank Mr. Veli Vikberg (Turenki, Finland) for determining the parasites and Mr. Kimmo Silvonen (Espoo, Finland) for his help in processing the photographs of the imagos.

\section{References}

Beck, H. 1960: Die Larvalsystematik der Eulen. — Abhandlungen zur Larvalsystematik der Insekten 4, Berlin. 406 pp.

Beck, H. 1974: Zur Beschreibung der Zeichnung (Ornamentik) von Insektenlarven. Eine Anleitung am Beispiel von Noctuidenlarven. - Atalanta 5: 121-143.

Fibiger, M. 1990: Noctuinae I. — Noctuidae Europeae 1, Sorø. 208 pp.

Fibiger, M. 1997: Noctuinae III. — Noctuidae Europeae 3, Sorø. $418 \mathrm{pp}$.

Hinton, H. E. 1946: On the homology and nomenclature of the setae of lepidopterous larvae, with some notes on the phylogeny of the Lepidoptera. - Trans. R. Ent. Soc. Lond. 97: 1-37.

Kozhanchikov, I. V. 1937: Lepidoptera, Noctuidae (Agrotinae). — Fauna of USSR, vol. XIII, part 3, Moscow-Leningrad.

Mentzer, E. von \& Moberg, A. 1987: Agrotis luehri sp. n. from Norway and its relation to the group Agrotis fatidica (Hübner) (Lepidoptera, Noctuidae). — Entomologisk Tidskrift 108: 33-43.

Patocka, J. 1996: Die Puppen der mitteleuropäischen Eulen: Cuculliinae, Heliothinae, Ipimorphinae, Hadeninae, Agrotinae (Lepidoptera, Noctuidae). — Nova Supplementa Entomologica 8. 